\title{
Quantifying a Sustainable Management Space for Human Use of Coastal Groundwater under Multiple Change Pressures
}

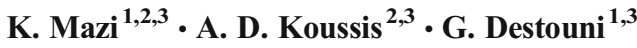

Received: 1 July 2015 / Accepted: 18 May 2016/

Published online: 9 June 2016

C The Author(s) 2016. This article is published with open access at Springerlink.com

\begin{abstract}
In the densely populated coastal regions of the world, loss of groundwater due to seawater intrusion, driven by changes of climate, sea level, land use and water use, may critically impact many people. We analytically investigate and quantify the limits constraining a coastal aquifer's sustainable management space, in order to avoid critical loss of the coastal groundwater resource by seawater intrusion. Limiting conditions occur when the intrusion toe reaches the pumping wells, well intrusion, or the marine-side groundwater divide, complete intrusion; in both cases the limits are functions of the seaward groundwater flow remaining after the human groundwater extractions. The study presents a screening-level approach to the quantification of the key natural and human-determined controls and sustainability limits for the human use of coastal groundwater. The physical and geometrical characteristics of the coastal aquifer along with the natural conditions for recharge and replenishment of the coastal groundwater are the key natural controls of the sustainable management space for the latter. The groundwater pumping rates and locations are the key human-determined controls of this space. The present approach to combining and accounting for both of these types of controls is
\end{abstract}

\section{Highlights}

- A general screening-level framework for evaluating sustainable coastal aquifer management options.

- Identified critical conditions in an exploited coastal aquifer: well, or complete aquifer intrusion.

- Simple \& general Sustainable Management Space quantified based on key natural \& pumping controls.

- Sustainability bounds are directly related to remaining groundwater flow after pumping.

- Rule of thumb is derived for 1st-order regional threat and management assessment of coastal aquifers.

Electronic supplementary material The online version of this article (doi:10.1007/s11269-016-1363-1) contains supplementary material, which is available to authorized users.

K. Mazi

kmazi@noa.gr

1 Department of Physical Geography, Bolin Centre for Climate Research, Stockholm University, SE-106 91 Stockholm, Sweden

2 Institute for Environmental Research and Sustainable Development, National Observatory of Athens, I. Metaxa \& Vas. Pavlou Str, GR-152 36 Athens, Palea Penteli, Greece

3 Navarino Environmental Observatory (NEO), Messinia, GR-240 01 Kalamata, Greece 
simple, yet general. The approach is applicable across different scales and regions, and for historic, current and projected future conditions of changing hydro-climate, sea level, and human freshwater use. The use of this approach is also concretely demonstrated for the natural and human-determined controls and limits of the sustainable management space for two specific Mediterranean aquifers.

Keywords Seawater intrusion · Coastal aquifer - Sustainable water management · Sustainability limits $\cdot$ Groundwater use $\cdot$ Mediterranean aquifers

\section{Introduction}

In 2001, over half the world's population lived within $200 \mathrm{~km}$ of a coastline, and eight of the ten largest cities in the world are located by the coast; http:/www.oceansatlas.org/. In the typically densely populated coastal regions, people rely often, and largely, on groundwater for drinking, food production and their economies. This is true especially for semi-arid regions and more so for arid coastal regions, which may be water-stressed or even water-deprived when densely inhabited; the Middle East and North Africa are pertinent examples (Leas et al. 2014). If coastal aquifers are exploited intensively, i.e., the groundwater abstractions substantially modify the aquifer conditions (Llamas and Custodio 2003), the naturally occurring seawater intrusion (SWI) increases and can threaten large-scale contamination of the coastal groundwater resource. Through progressive salinization, the groundwater will then become non-potable and the seawater may eventually invade pumping wells entirely; potable water standard is $500 \mathrm{ppm}$ TDS, corresponding to water mixture with $2 \%$ seawater of average-ocean salinity (35,000 ppm TDS).

Coastal regions are also exposed to other hydro-climatic changes and associated alterations of aquifer forcing on both the land and the marine side. Land-side changes may be related to climate change and to various changes in land- and water-use (Destouni et al. 2013; Jaramillo and Destouni 2014), not least due to agricultural irrigation that accounts for two thirds of world-water use (Postel 1997; Jaramillo and Destouni 2015). Such land-side changes are in addition to the direct intensive and rising use of coastal groundwater by increasing coastal populations and tourism (Llamas and Custodio 2003; Parry et al. 2007; Ferguson and Gleeson 2012). Marine-side changes are related to climate-driven sea-level change.

In particular, SWI in coastal aquifers is sensitive to altered aquifer forcing, in terms of groundwater level and seaward flow. Such alterations are implied by increased groundwater use (Llamas and Custodio 2003; Post 2005; Ferguson and Gleeson 2012; Mazi 2014), but also by overall hydro-climatic variability (Prieto and Destouni 2005; Prieto et al. 2006) and climate-driven change, such as reduction in groundwater recharge (Döll 2009; Small 2005) and sea-level rise (Nicholls and Klein 2005; Masterson and Garabedian 2007; Werner and Simmons 2009; Webb and Howard 2011; Loáiciga et al. 2012; Mazi et al. 2013). If the aquiferforcing regime is thusly altered, certain thresholds or tipping points (Lenton 2011) can be nonlinearly approached and ultimately crossed, causing drastic shifts in SWI (Mazi et al. 2013). The high non-linearity of the SWI response to forcing changes (Werner and Simmons 2009) implies that, after a tipping point has been crossed, even a minor further forcing change can greatly enhance SWI into the coastal aquifer.

To relatively simply address and quantify the SWI response to forcing changes, Koussis et al. (2012) developed an analytical framework that extends previous analytical solutions 
(Strack 1976). This extended framework has been used, for instance, to assess the proximity of prominent Mediterranean aquifers to the site-specific critical thresholds that determine the above-mentioned tipping points under prevailing aquifer conditions (Mazi et al. 2014, Mazi

(a)

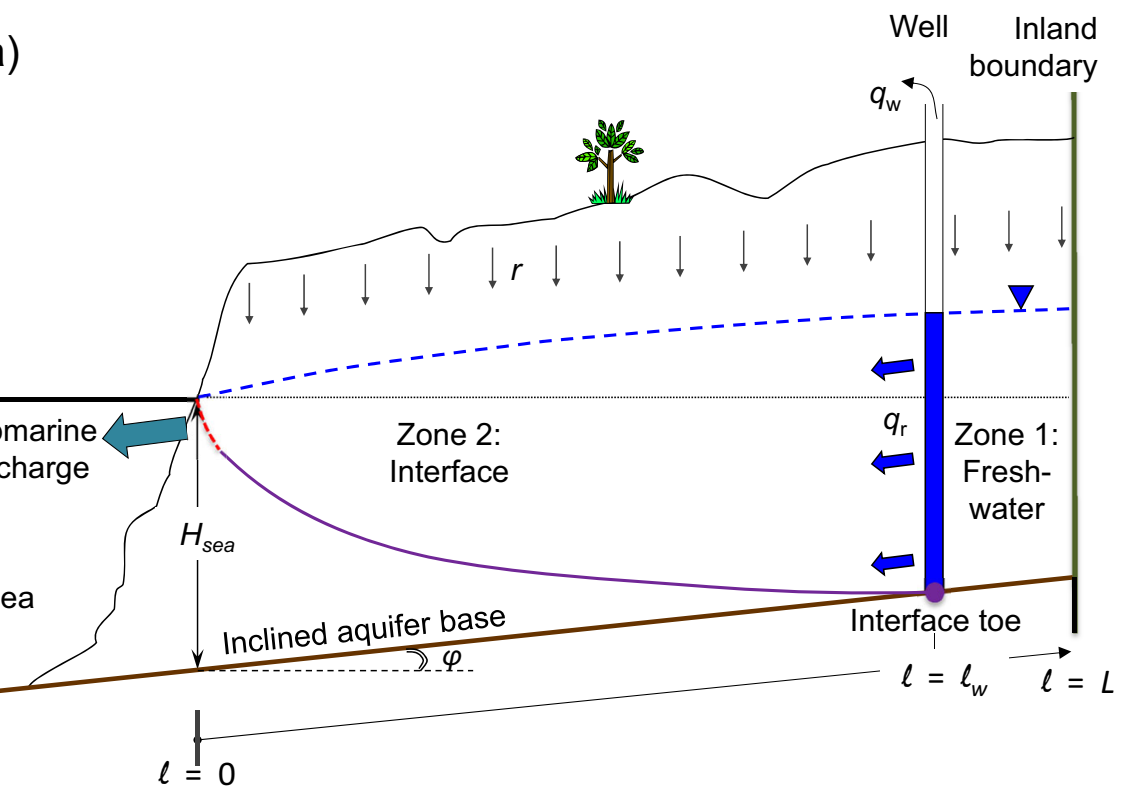

(b)

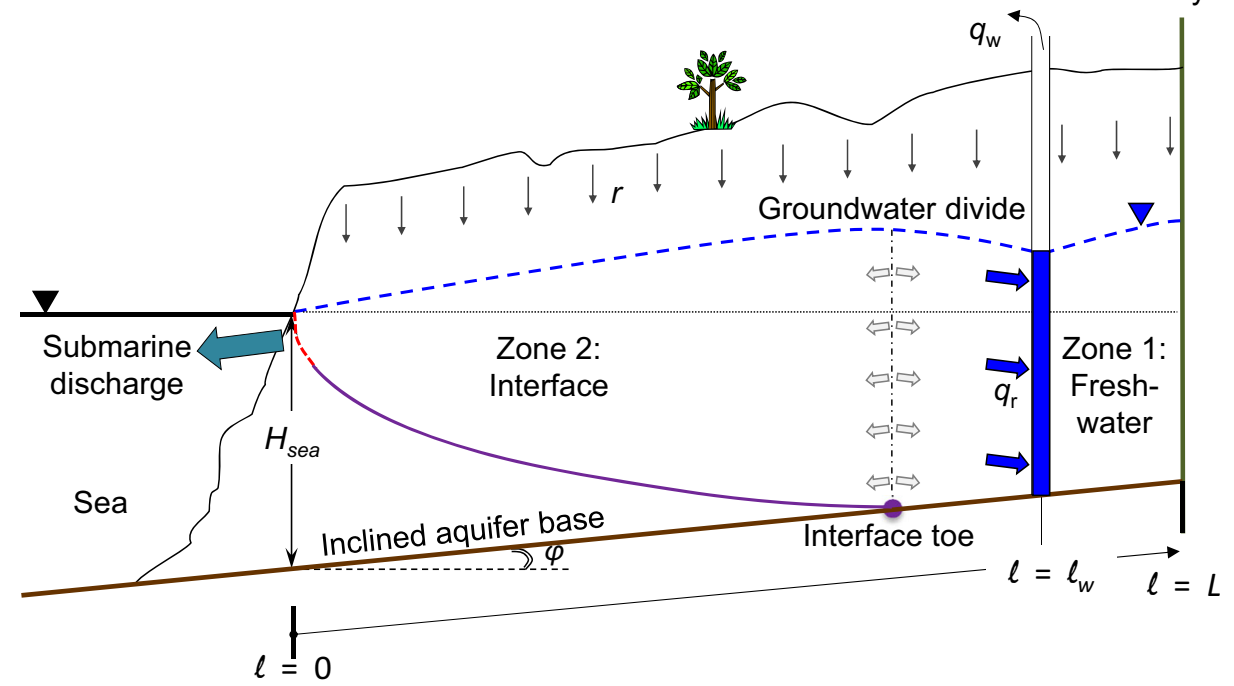

Fig. 1 Critical seawater intrusion in a coastal aquifer: a intrusion into water supply wells, with the toe of seawater-freshwater interface reaching the well location; b complete intrusion into the coastal aquifer, with the interface toe reaching the coastal groundwater divide (point of maximum resistance to intrusion), which may be located between the pumping well and the coast (Mazi 2014) 
2014). Such thresholds may concern intrusion to key water supply wells (Fig. 1a) or complete intrusion up to the groundwater divide (Fig. 1b) in a coastal aquifer.

In general, analytical interface-flow solutions, although far less complete than variable-density solutions, offer clarity of interpretation, require few data and are far more readily evaluated, hence also better amenable to stochastic analyses. Such analytical solutions are thus suitable for first-order regional-scale assessments of coastal aquifer vulnerability to SWI (Mazi et al. 2014), as well as for screening of aquifer management scenarios (Koussis et al. 2012). Numerical variable-density solutions can complement screening-level solutions by studying in detail cases of particular interest, accounting for irregular multi-dimensional geometries and hydrogeological heterogeneities, provided adequate field data support the detailed simulations (Sanford and Pope 2010).

Controlling the threats to coastal groundwater discussed above requires monitoring and managing of the coastal aquifers, not only for meeting present-day water demand and supply, but also regarding long-term sustainability. Sustainability is defined as the ethical obligation to ensure that the current use of a resource does not compromise its use by future generations (World Commission on Environment and Development 1987). Complex hydrogeology, variable natural and human-controlled forcing and demand, all exacerbated by uncertainty, make meeting this sustainability obligation for the groundwater resource a formidable task. Hydrogeological concepts relating to such aquifer management include an ambiguous safe yield (Llamas and Custodio 2003) as a possible simple rule against overdraft, with the latter defined as groundwater withdrawals exceeding the aquifer recharge, and various other vulnerability indicators (Werner et al. 2012). Executing this management task employs then typically advanced flow models, combined with optimisation considering technological options and socio-economics (Koussis et al. 2010a, 2010b; Stigter et al. 2015; Zuurbier et al. 2016).

To complement such detailed and site-specific management approaches, the present study develops a general screening-level framework for evaluating sustainable management options for coastal groundwater under various possible, current and future, aquifer and hydro-climatic conditions. This is done in terms of a set of key, inter-linked yet readily calculated, natural and human-controlled limits to the use of coastal groundwater for avoiding its critical loss by SWI. Such framework development and its quantification are needed and useful for first-order regional assessment of main threats and management options for the regional resource of coastal fresh groundwater (Ferguson and Maxwell 2012), for example for water-stressed or water-deprived coastal regions such as the Middle East and North Africa. In this study, natural and human-controlled limits are derived and define a sustainable management space (SMS) for the human use of coastal groundwater resources. This general concept is here also concretely applied to and quantified for the Israel Coastal Aquifer (ICA) and the Cyprus Akrotiri Aquifer (CAA).

The concrete exemplification of the use of the general screening framework for these two regional aquifers of the Southeastern Mediterranean is motivated by their importance as freshwater sources for the local populations and for this region's economic prosperity (details in Mazi et al. 2014). The Southeastern Mediterranean region is particularly threatened by reduced groundwater recharge (Döll 2009; Bring et al. 2015) along with many additional change pressures from human activity developments over at least the last 50 years (Mazi et al. 2014), which have all affected and will continue to affect SWI into the coastal groundwater resources of this region. 


\section{Method}

In this study we use and further develop the analytical framework of Koussis et al. (2012), enhanced and refined in Koussis et al. (2015). The conceptualization of the coastal groundwater system (Fig. 1) represents an inclined $(\sin \varphi)$ unconfined aquifer, with base depth at the coast $H_{\text {sea }}$ below sea-level, average hydraulic conductivity $K$, and length $L$ to a land-boundary, with either known flow, e.g., zero-flow at an impervious boundary or groundwater divide, or known hydraulic head; the $\ell$-axis follows the aquifer base, starting at $H_{\text {sea }}$ below the intersection of the sea surface. The aquifer is recharged by precipitation (and possibly artificially) minus evapotranspiration at resulting net rate $r$, in addition to land-boundary inflow $q_{\mathrm{b}}$. Human control conditions are quantified in terms of a representative regional groundwater pumping rate $q_{\mathrm{w}}$ at a representative (e.g., flow-weighted average) location from the coast $\ell_{\mathrm{w}}$ (Destouni and Prieto 2003; Prieto and Destouni 2005; Koussis et al. 2010a, 2010b). SWI is quantified by the toe of a nominal seawater-freshwater interface located at distance $\ell_{\mathrm{T}}$ from the coast, interpreted as the $50 \%$-salinity isoline in the transition zone between fresh groundwater and seawater. Online Material 1 summarises the analytical model.

\subsection{Determining a Sustainable Management Space (SMS)}

Identification and quantification of a regional SMS departs from the groundwater flow $q_{\mathrm{r}}$ directly after the location $\ell_{\mathrm{w}}$ of groundwater pumping at rate $q_{\mathrm{w}}$ :

$$
q_{\mathrm{r}}=r\left(L-\ell_{\mathrm{w}}\right)-q_{\mathrm{w}}-q_{\mathrm{b}}
$$

We shall henceforth call $q_{\mathrm{r}}$ the groundwater outflow remaining after pumping, with the understanding that it can be truly remaining, i.e. flowing seawards: $q_{\mathrm{r}}>0$, or flowing towards the well: $q_{\mathrm{r}}<0$; thus, $q_{\mathrm{r}}>0$ is hydraulically negative (flux in the $-\ell$ direction). This sign reversal is management-suitable. That groundwater flow $q_{\mathrm{r}}$ links to the fresh groundwater outflow to the sea $q_{\mathrm{SD}}$ through the relation $q_{\mathrm{SD}}=-r L+q_{\mathrm{w}}+q_{\mathrm{b}}=-q_{\mathrm{r}}-r \ell_{\mathrm{w}}$ (Mazi et al. 2013); $q_{\mathrm{SD}}$ corresponds to the freshwater component of total submarine groundwater discharge (Destouni and Prieto 2003). The limits on the groundwater extraction $\left(q_{\mathrm{w}}\right)$ that are allowed by the natural regional groundwater recharge $(r)$ and are required for sustainable groundwater management are thus quantifiable in terms of the groundwater flux $q_{\mathrm{r}}$ that must remain after pumping so that the fresh groundwater outflow to the sea, $q_{\mathrm{SD}}$, can resist critical SWI.

The limits on $q_{\mathrm{r}}$ are derived and quantified in this study, considering for simplicity a no-flow inland boundary condition. This simplification represents a conservative SMS assessment: it expects the total recharge (to the land boundary, $r L$ ) of coastal groundwater alone (without groundwater inflow $q_{\mathrm{b}}$ through the land boundary) to yield a fresh groundwater flux to the sea $\left(q_{\mathrm{SD}}\right)$ that suffices to resist critical SWI. To fully control SWI, however, monitoring of the groundwater table (hydraulic head) and management triggered by too low groundwater levels are also needed to assess boundary flows and complement the flux-based management approach exemplified in this study (Werner et al. 2011). 
Based on the analytical framework of Koussis et al. (2012), we can identify the following general conditions for the critical case of SWI into the representative well location $\ell_{\mathrm{w}} / L$ (illustrated in Fig. 1a; red dashed line in Fig. 2a)

$$
\frac{\ell_{\mathrm{T}}}{L}=\frac{\ell_{\mathrm{w}}}{L} \quad \text { for } 0 \leq q_{\mathrm{r}}>q_{\mathrm{r}}^{\max }
$$

and the critical case of complete SWI intrusion into the coastal aquifer up to its defining coastal groundwater divide (illustrated in Fig. 1b; blue solid line in Fig. 2a; eq. A5 in Online Material 1):

$$
\frac{\ell_{\mathrm{T}}}{L}=\frac{\ell_{\mathrm{div}}}{L}=\frac{1}{r L} q_{\mathrm{r}}+\frac{\ell_{\mathrm{w}}}{L} \text { for } q_{\mathrm{r}}^{\min }<q_{\mathrm{r}}>0
$$

These conditions are further quantified and illustrated in the Results section. Here, we note that Eqs. 2a-b form a general basis for delimiting an SMS for coastal groundwater, as illustrated in Fig. 2a.

For the critical case of well intrusion (Fig. 1a; Eq. 2a; red dashed line in Fig. 2a), the location of the SWI interface toe $\left(\ell_{\mathrm{T}} / L\right)$ is by definition the representative well location, i.e., $\ell_{\mathrm{T}} / L=\ell_{\mathrm{w}} / L$. The naturally bounded upper limit $\left(q_{\mathrm{r}}{ }^{\max }\right)$ of the seaward groundwater

Fig. 2 Schematic representation of SMS (grey). The limits of the SMS for coastal groundwater are shown for given relative well location $\ell_{\mathrm{w}} / L$, as determined by critical complete intrusion (blue line, corresponding to intrusion conditions in Fig. 1b) and critical well intrusion (red line, corresponding to intrusion conditions in Fig. 1a). In a the relative intrusion toe location $\ell_{\mathrm{T}} / L$ is shown for given groundwater recharge rate $r$ and aquifer extent $L$ under variable groundwater flow remaining directly after pumping $q_{\mathrm{r}}$, and in $\mathbf{b} q_{\mathrm{r}}$ is shown for given $L$ and variable $r$

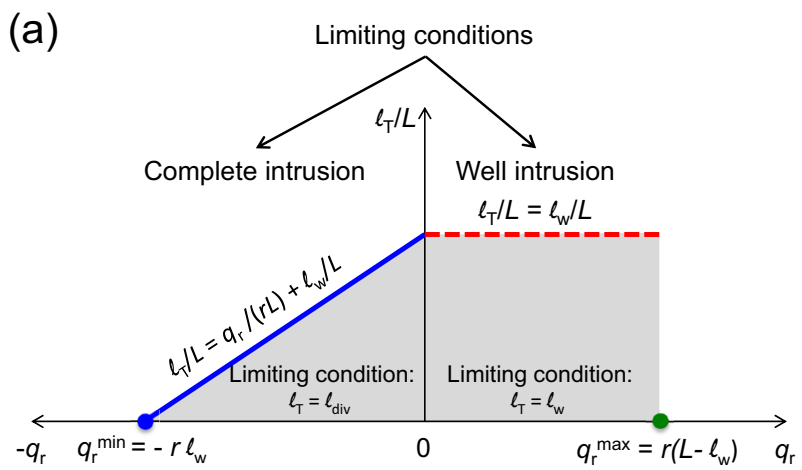

(b)

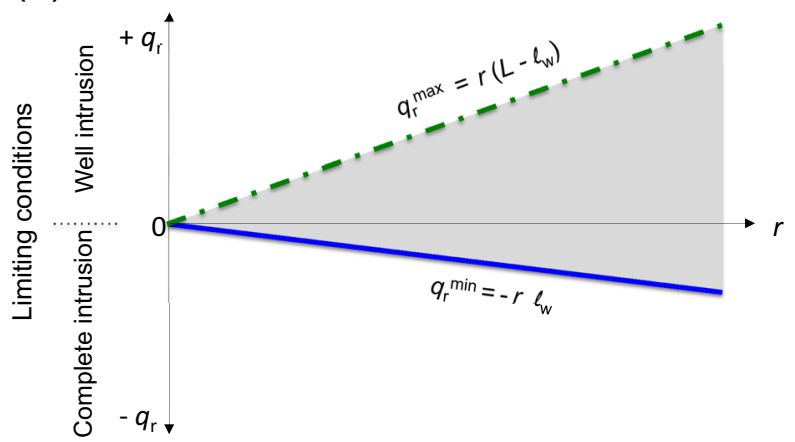


flow $q_{\mathrm{r}}$ is then $q_{\mathrm{r}}^{\max }=r\left(L-\ell_{\mathrm{w}}\right)$, which applies to zero pumping $\left(q_{\mathrm{w}}=0\right)$ in the coastal aquifer. Well intrusion (Fig. 1a) is also the limiting critical case for any $q_{\mathrm{r}} \geq 0$, because positive $q_{\mathrm{r}}$ in Eq. $2 \mathrm{~b}$ for the alternative critical case of complete aquifer intrusion implies $\ell_{\mathrm{T}} / L>\ell_{\mathrm{w}} / L$. That is, Eq. $2 \mathrm{~b}$ for $q_{\mathrm{r}} \geq 0$ yields deeper SWI than $\ell_{\mathrm{w}} / L$, implying that the critical well intrusion limit $\ell_{\mathrm{T}} /$ $L=\ell_{\mathrm{w}} / L$ (Fig. 1a) is reached before the alternative critical limit $\ell_{\mathrm{T}} / L=\ell_{\text {div }} / L$ for complete intrusion (Fig. 1b).

For the case of complete aquifer intrusion (Fig. 1b; Eq. 2b; blue solid line in Fig. 2a), Eq. $2 \mathrm{~b}$ implies that the critical location of the interface toe $\left(\ell_{\mathrm{T}} / L\right)$ is a function of $q_{\mathrm{r}}^{\mathrm{min}}<q_{\mathrm{r}} \leq 0$, i.e., of negative $q_{\mathrm{r}}$ until a lowest limit $q_{\mathrm{r}}^{\mathrm{min}}=-r \ell_{\mathrm{w}} ; q_{\mathrm{r}}^{\mathrm{min}}$ is the zero-value of Eq. $2 \mathrm{~b}$ (for maximum possible pumping). For any given value of net recharge rate $r$, the slope of the critical line segment for this negative- $q_{\mathrm{r}}$ range is $(r L)^{-1}$.

The allowance of negative remaining $q_{\mathrm{r}}$ after pumping implies that more fresh groundwater can be sustainably withdrawn by pumping $q_{\mathrm{w}}$ at $\ell_{\mathrm{w}}$ than is recharged inland of $\ell_{\mathrm{w}}$. This is so because pumping draws fresh groundwater from both a landward and a seaward zone around $\ell_{\mathrm{w}}$ and can be sustained as long as the resulting coastal groundwater divide $\ell_{\text {div }}$ and the resulting intrusion toe $\ell_{\mathrm{T}}$ remain seaward of $\ell_{\mathrm{w}}$.

As both the upper $q_{\mathrm{r}}$ limit $q_{\mathrm{r}}^{\max }=r\left(L-\ell_{\mathrm{w}}\right)$ and the lower $q_{\mathrm{r}}$ limit $q_{\mathrm{r}}^{\min }=-r \ell_{\mathrm{w}}$ depend on the net recharge rate $r$, the SMS may also be illustrated as function of $r$ (Fig. 2b). This $r$-space illustration of the SMS complements that for a fixed $r$ (Fig. 2a). The full shaded area in Fig. 2b represents the general SMS, falling between the upper bound of $q_{\mathrm{r}}^{\max }=r\left(L-\ell_{\mathrm{w}}\right)$ (green dashed line) and the lower bound of $q_{\mathrm{r}}^{\min }=-r \ell_{\mathrm{w}}$ (blue solid line). The total site-specific range of sustainable $q_{\mathrm{r}}$ is the vertical line of $q_{\mathrm{r}}^{\min }<q_{\mathrm{r}}>q_{\mathrm{r}}^{\max }$ for the given site-specific $r$ value. The partitioning of the site-specific range of sustainable $q_{\mathrm{r}}$ between the positive segment $0 \leq q_{\mathrm{r}} \leq q_{\mathrm{r}}{ }^{\max }$ and the negative segment $q_{\mathrm{r}}^{\min }<q_{\mathrm{r}} \leq 0$ represents the fresh-groundwater fraction drawn from the landside (limited by the critical case of well intrusion; Fig. 1a) and from the seaside (limited by the critical case of complete intrusion; Fig. 1b) around the pumping location $\ell_{\mathrm{w}}$, respectively.

\subsection{Exploring Specific Aquifer Vulnerability Relative to its SMS}

The results presented in the sequel go beyond common effect analysis: by using the abovedeveloped general framework, we investigate how SMS results change for various combinations of naturally given aquifer and hydro-climatic conditions (hydraulic conductivity $K$, coastal aquifer extent $L$, slope $\sin \varphi$ and depth below sea level $H_{\text {sea }}$, and groundwater recharge rate $r$ ) and human-determined exploitation choices (pumping $q_{\mathrm{w}}$, and pumping location $\ell_{\mathrm{w}}$ ). Table 1 summarizes the parameter value ranges used in this analysis to typologize the SWI and associated SMS behaviour across a realistic range of conditions that may prevail around the world.

Generic aquifer results are illustrated in terms of the SMS for some realistic fixed conditions (corresponding to Fig. 2a) and for variable conditions (corresponding to Fig. 2b) of net recharge rate $r$ across a range of different possible pumping locations $\ell_{\mathrm{w}} / L$. Furthermore, site-specific controls and limits of SMS are also concretely quantified for the study aquifers ICA (Israel) and CAA (Cyprus), aiming to trace the groundwater-use and related SWI impacts in relation to the SMS of these coastal regions. 
Table 1 Characteristics and parameters used in the modelling of generic aquifers

\begin{tabular}{lll}
\hline & Constant & Range of variation \\
\hline Aquifer length, $L(\mathrm{~m})$ & 5000 & \\
Inland boundary condition & no-flow, $q_{b}=0$ & \\
Slope of impervious aquifer base, $\sin \varphi$ & 0.01 & $5-600$ \\
Depth of sea at the coast to the aquifer base, $H_{\text {sea }}(\mathrm{m})$ & & $500-4500$ \\
Well location, $\ell_{\mathrm{w}}(\mathrm{m})$ & $1-1000$ \\
Recharge rate, $r\left(\mathrm{~mm} \mathrm{yr}^{-1}\right)$ & & 1 and 30 \\
Hydraulic conductivity, $K\left(\mathrm{~m} \mathrm{~d}^{-1}\right)$ & $8.3-1000$ \\
$L / H_{\text {sea }}:$ ratio of aquifer length to aquifer depth at the coast & \\
$\ell_{\mathrm{w}} / L:$ ratio of pumping location to aquifer length & \\
$\ell_{\mathrm{w}} / H_{\text {sea }}:$ ratio of pumping location to aquifer depth at the coast & \\
\hline
\end{tabular}

\section{Results}

\subsection{General and Specific Sustainable Management Space}

In an aquifer characterized geometrically by $L / H_{\text {sea }}$, moving the representative well location further inland (increasing $\ell_{\mathrm{w}} / L$, and thereby also $\ell_{\mathrm{w}} / H_{\text {sea }}$ ) allows for more pumping and smaller sustainable $q_{\mathrm{r}}$ before reaching the limit of complete intrusion. From the calculation results for different site conditions -Online Material 2, Fig. S1- follows that: (1) for any given location $\ell_{\mathrm{w}} / L$, aquifers with higher recharge rate $r$ allow for more pumping of fresh groundwater, and thus lower remaining $q_{\mathrm{r}}$; (2) for any given recharge rate $r$, sites with greater hydraulic conductivity $K$ imply greater SWI (greater $\ell_{\mathrm{T}} / L$ values) before a critical condition is reached.

In general, varying the $K$ value shifts (up-down) the SWI toe location $\ell_{\mathrm{T}} / L$ value under relatively small change in the range of sustainable $q_{\mathrm{r}}$ (Online Material 2, Fig. S1a-b), while varying the $r$ value shifts (left-right) the sustainable $q_{\mathrm{r}}$ range under relatively small change in the resulting $\ell_{\mathrm{T}} / L$ range (Fig. 3 and Online Material 2, Fig. S1c-d). Furthermore, aquifers at various sites may differ in terms of their geometrical ratio $\ell_{\mathrm{w}} / H_{\text {sea }}$. For any given combination of recharge $r$ and relative well position $\ell_{\mathrm{w}} / L$, greater remaining groundwater flow after pumping $q_{\mathrm{r}}$ (smaller pumping $q_{\mathrm{w}}$ ) is then required for sustainability in sites with smaller $\ell_{\mathrm{w}} /$ $H_{\text {sea }}$ (deeper aquifer and/or higher sea-level) (Fig. 3 and Online Material 2, Fig. S2).

Figure 4 (and Online Material 2, Fig. S3) show the total general SMS as function of $r$ (spanning all possible well locations relative to aquifer depth $0<\ell_{\mathrm{w}} / H_{\text {sea }} \rightarrow \infty$ ) for a generic aquifer with parameter value ranges outlined in Table 1 . The investigated ranges of relative well location $0.1<\ell_{\mathrm{w}} / L<0.9$ and groundwater recharge $1 \leq r \leq 1000 \mathrm{~mm} \mathrm{yr}^{-1}$ cover most $\ell_{\mathrm{w}} / L$ and $r$ values that can realistically prevail in different aquifers and world regions. Across these ranges then, the total general SMS (grey area in Fig. 4 and Online Material 2, Fig. S3) applies also specifically, in approximately its full extent, for all site conditions of $\ell_{\mathrm{w}} / H_{\text {sea }}>40$ or hydraulic conductivity $K \leq 1 \mathrm{~m} \mathrm{~d}^{-1}$. It is only for the complementary combination of sitespecific conditions $\ell_{\mathrm{w}} / H_{\text {sea }} \leq 40$ and $K>1 \mathrm{~m} \mathrm{~d}^{-1}$ that the specific SMS is considerably smaller (hatched in Fig. 4 and Online Material 2, Fig.S3-S4) than the total general SMS. The reason for this bifurcation is that the site-specific lower $q_{\mathrm{r}}$ limit (determined from $\ell_{\mathrm{T}}=\ell_{\mathrm{div}}>0$ ) approaches rapidly the general lower limit $q_{\mathrm{r}}^{\mathrm{min}}=-r \ell_{\mathrm{w}}$ (implying $\ell_{\mathrm{T}}=\ell_{\text {div }}=0$ and $\ell_{\mathrm{w}} / H_{\text {sea }} \rightarrow \infty$ ) with 


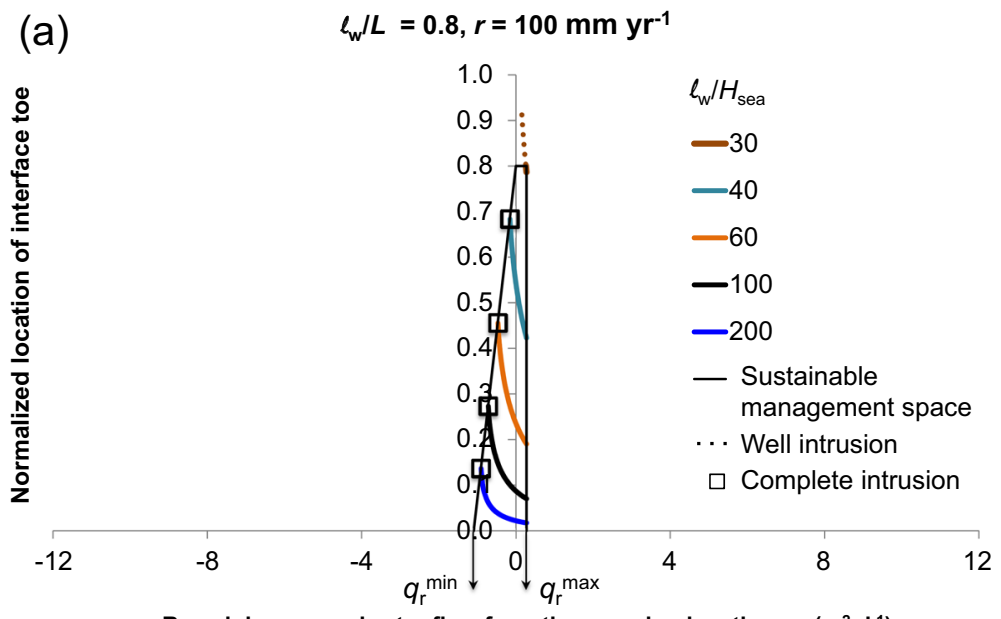

Remaining groundwater flow from the pumping location, $q_{r}\left(m^{2} \mathrm{~d}^{-1}\right)$

(b)

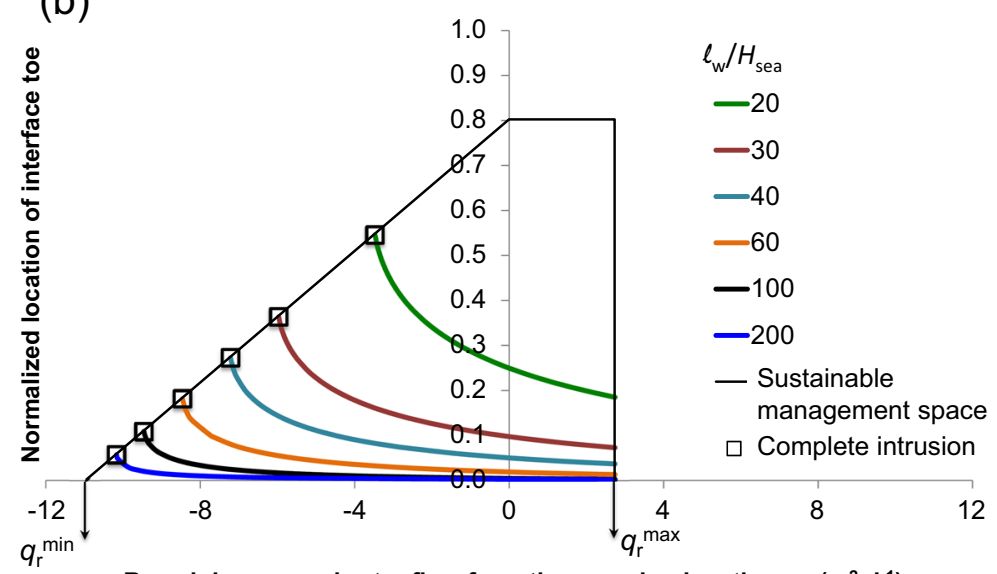

Remaining groundwater flow from the pumping location, $q_{r}\left(m^{2} d^{-1}\right)$

Fig. 3 Intrusion curves revealing SMS for coastal groundwater. Results are shown for two different relations between well position and coastal aquifer depth $\ell_{\mathrm{w}} / H_{\text {sea }}$, under given aquifer recharge rate $r$ and relative well location $\ell_{\mathrm{w}} / L$; in all illustrated cases, hydraulic conductivity $K=30 \mathrm{~m} \mathrm{~d}^{-1}$. In terms of groundwater flow remaining after pumping, the SMS extends from the upper-most limit $q_{\mathrm{r}}^{\max }=r\left(L-\ell_{\mathrm{w}}\right)$ for zero-pumping to the lowest limit $q_{\mathrm{r}}^{\min }=-r \ell_{\mathrm{w}}$ (for zero-value of the line Eq. 2), which is approached asymptotically as $\ell_{\mathrm{w}} / H_{\text {sea }} \rightarrow \infty$

increasing $\ell_{\mathrm{w}} / H_{\text {sea }}$ and is close to it for $\ell_{\mathrm{w}} / H_{\text {sea }}>40$ (Fig. 3). Figs. S4-S5 in Online Material 2 show further details of the site-specific SMS for aquifers with different $\ell_{\mathrm{w}} / H_{\text {sea }}$ (and $K$ ) and how it approaches the total general SMS as $\ell_{\mathrm{w}} / H_{\text {sea }} \rightarrow \infty$.

The results in Fig. 4 thus identify a general rule of thumb for two complementary site condition combinations: (a) the total general SMS delimited by $-r \ell_{\mathrm{w}}<q_{\mathrm{r}} \leq r\left(L-\ell_{\mathrm{w}}\right)$ (total grey, Fig. 4) is sustainable for aquifer site conditions $\ell_{\mathrm{w}} / H_{\text {sea }}>40$ or hydraulic conductivity $K \leq 1 \mathrm{~m} \mathrm{~d}^{-1}$; (b) the more restricted SMS for $0<q_{\mathrm{r}} \leq r\left(L-\ell_{\mathrm{w}}\right)$ (hatched, Fig. 4) is sustainable for aquifer site conditions $\ell_{\mathrm{w}} / H_{\text {sea }} \leq 40$ and $K>1 \mathrm{~m} \mathrm{~d}^{-1}$. 


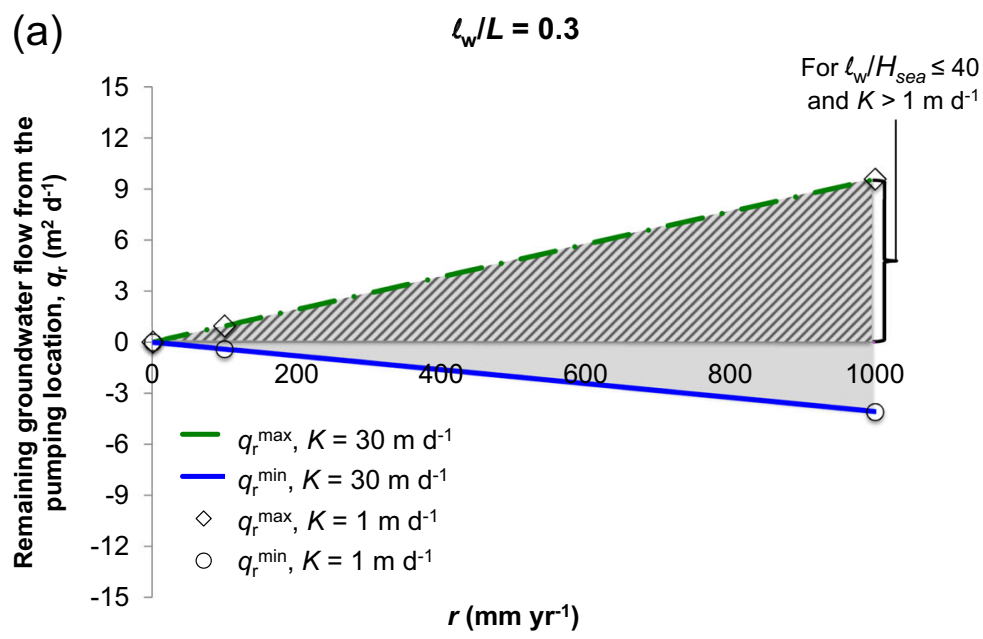

(b) $\quad \ell_{w} / L=0.9$

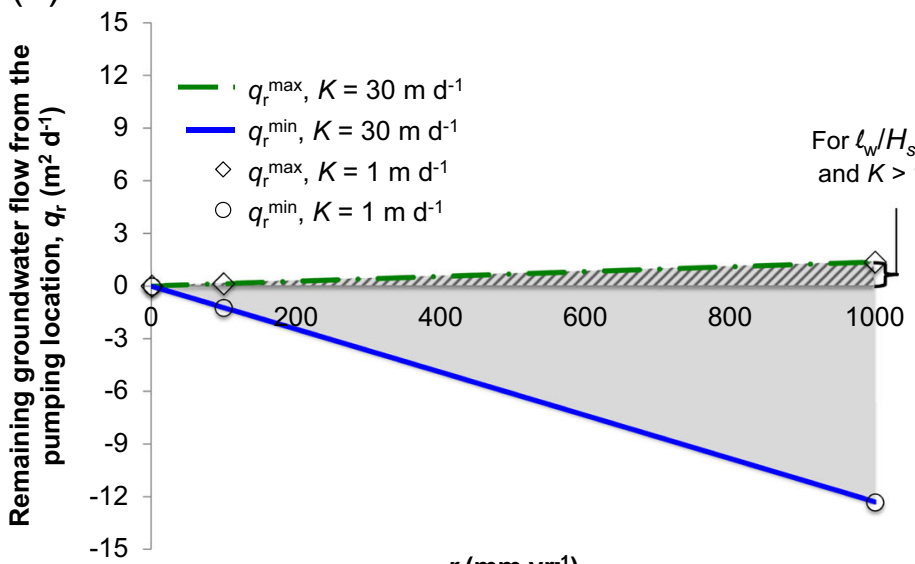

$r\left(m m y^{-1}\right)$

Fig. 4 SMS for use of coastal groundwater. The general SMS area (whole grey area) is quantified for all possible well location relations to aquifer depth $\left(0<\ell_{\mathrm{w}} / H_{\mathrm{sea}} \rightarrow \infty\right)$ in terms of the general upper $\left(q_{\mathrm{r}}^{\max }\right.$, dashed line $)$ and lower $\left(q_{\mathrm{r}}^{\mathrm{min}}\right.$, solid line) limits of groundwater flow $q_{\mathrm{r}}$ remaining after pumping as function of groundwater recharge rate $r$. Results are shown for two different well locations relative to total aquifer extent $\left(\ell_{\mathrm{w}} / L\right)$ and hydraulic conductivity values $K$. For site conditions of $\ell_{\mathrm{w}} / H_{\text {sea }}>40$ or $K \leq 1 \mathrm{~m} \mathrm{~d}^{-1}$, the general space (grey) is approximately applicable also as site-specific SMS. For the complementary site conditions $\ell_{\mathrm{w}} /$ $H_{\text {sea }} \leq 40$ and $K>1 \mathrm{~m} \mathrm{~d}^{-1}$, the site-specific SMS is restricted to the hatched space part, with Figs. S3-S5 in Online Material 2 showing further details of how the site-specific SMS is determined for different aquifer cases in terms of site-specific $\ell_{\mathrm{w}} / H_{\text {sea }}$ and $K$

Part (a) of the identified rule of thumb reflects that even negative $q_{\mathrm{r}}$ is sustainable for aquifers with either relatively low conductivity $\left(K \leq 1 \mathrm{~m} \mathrm{~d}^{-1}\right)$ or relatively small aquifer depth below sea level $\left(\ell_{\mathrm{w}} / H_{\mathrm{sea}}>40\right)$, so that fresh groundwater can be pumped from both the seaside and the landside of the representative well location $\ell_{\mathrm{w}} / L$, as long as $q_{\mathrm{r}}$ remains above the general lower limit $q_{\mathrm{r}}^{\mathrm{min}}=-r \ell_{\mathrm{w}}$. Part (b) of the rule reflects that $q_{\mathrm{r}}$ must remain positive for aquifers with both relatively high conductivity $\left(K>1 \mathrm{~m} \mathrm{~d}^{-1}\right)$ and relatively large 
aquifer depth below sea level $\left(\ell_{\mathrm{w}} / H_{\mathrm{sea}} \leq 40\right)$, so that only groundwater recharged on the landside of $\ell_{\mathrm{w}} / L$ can be pumped sustainably.

Overall, the total grey area of the general SMS in Fig. 4 is the same, regardless of management-chosen well location $\ell_{\mathrm{w}} / L$ or prevailing aquifer $K$-value. This is because the recharge rate $r$ ultimately determines the available flow of fresh groundwater that can be partitioned between pumped water and remaining flow left to resist critical SWI as submarine groundwater discharge $q_{\mathrm{SD}}$ (Destouni and Prieto 2003; Destouni et al. 2008; Prieto and Destouni 2011). A choice of farther inland well location (greater $\ell_{\mathrm{w}} / L$ ) will increase the negative relative to the positive part of the general SMS (Fig. 4), implying that more of the sustainable groundwater withdrawal can come from the seaside and less from the landside of $\ell_{\mathrm{w}} / L$. Furthermore, pumping more inland will make complete intrusion, rather than well intrusion, the likely limiting condition. Conversely, pumping more seaward will increase the positive relative to the negative part of the total SMS and make well intrusion more likely as limiting condition.

\subsection{Concrete Site-Specific Implications of the SMS}

Mazi et al. (2014) have studied and modelled SWI conditions in the specific aquifer cases of ICA and CAA, considering different pumping locations and pumping rates under their current net recharge; we refer to that work for detailed site and analysis descriptions. Here, the SMS for these sites is determined for variable net recharge $r$ (to capture possible effects of changed $r$ due to changes in human groundwater use, hydro-climatic change and/or artificial recharge) and two alternative pumping locations. The presented analysis enables calculating and visualising the implications of the current pumping rate for current and possibly changed recharge conditions. We further determine the minimum $r$-value required for sustaining the current pumping rate within the site-specific SMS. In Online Material 2, Figs. S6 and S7 show, respectively for the ICA and CAA aquifers, (a) the maps with the investigated profile sections and (b) the crosssections as schematized in the present modelling, with the main geometrical and physical characteristics, along with the aquifer recharge rates, freshwater inflows and exploitation schemes (locations of fully penetrating troughs and pumping rates). Table-T1 in Online Material 2 summarizes the parameters of the conceptual cross-sections of the ICA and the CAA.

\subsubsection{Israel Coastal Aquifer (ICA)}

The ICA has an area of $\sim 1900 \mathrm{~km}^{2}$, its depth exposure to the sea is $H_{\text {sea }} \approx 200 \mathrm{~m}$ with $L /$ $H_{\text {sea }}=100$, the inclination of its $20-\mathrm{km}$ long base is $1 \%$, its mean hydraulic conductivity $K=30 \mathrm{~m} \mathrm{~d}^{-1}$, and the recharge rate $240 \mathrm{~mm} \mathrm{yr}^{-1}$; pumping is $q_{\mathrm{w}}=3000 \mathrm{~m}^{2} \mathrm{yr}^{-1}$ at $\ell_{\mathrm{w}}=3 \mathrm{~km}$. The interface toe position for these current conditions is calculated by the analytical model to be $\ell_{\mathrm{T}}=2.6 \mathrm{~km}$ (Mazi et al. 2014).

Figure 5a shows the SMS for the resulting current values $\ell_{\mathrm{w}} / L=0.15$ and $\ell_{\mathrm{w}} / H_{\text {sea }}=15$ under variable recharge $r$; in that figure the cross $(+)$ indicates the current remaining groundwater flow $q_{\mathrm{r}}$ after the current pumping. The positive current $q_{\mathrm{r}}$ (cross, Fig. 5a) implies that, for this current pumping location, pumping is sustainable only from the area inland of the representative well location. The well intrusion condition $\ell_{\mathrm{T}}=\ell_{\mathrm{w}}$ (Fig. 1b) applies as the critical one for the current $r=240 \mathrm{~mm} \mathrm{yr}^{-1}$ and for all $r \leq 816 \mathrm{~mm} \mathrm{yr}^{-1}$ (calculated, not shown). For $r>816 \mathrm{~mm} \mathrm{yr}^{-1}$, the lower limit $q_{\mathrm{r}}^{\mathrm{min}}$ falls in the negative part of the sustainable space with complete intrusion $\ell_{\mathrm{T}}=\ell_{\text {div }}$ (Fig. 1a) as critical condition. 
(a) ICA

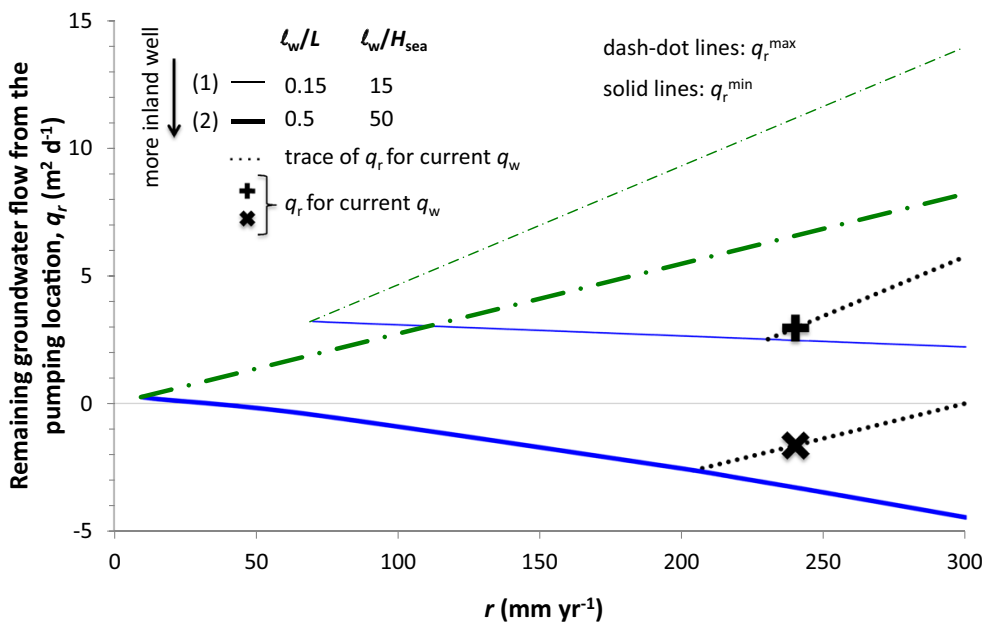

(b) CAA

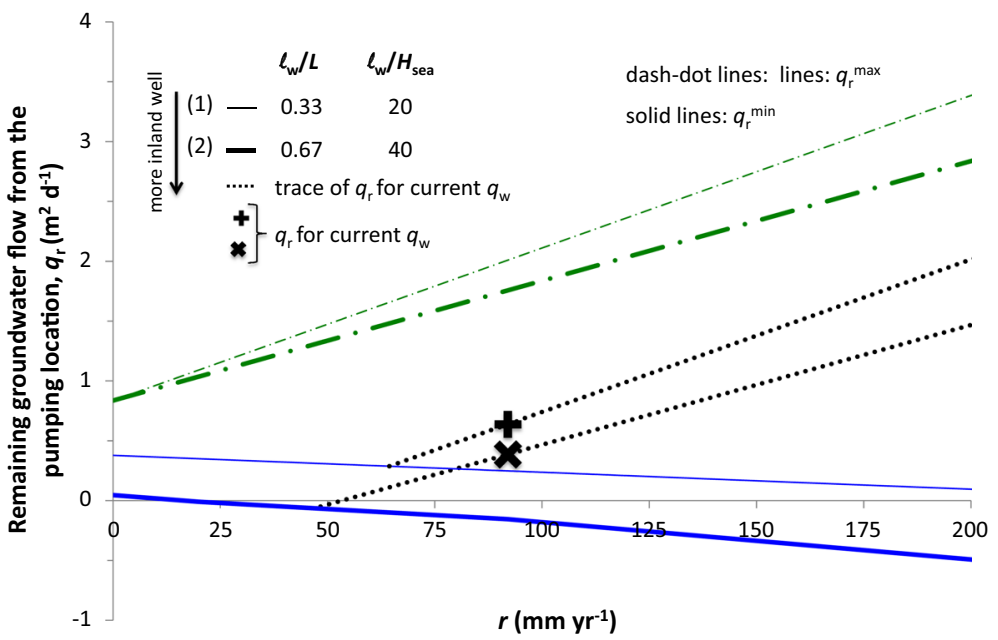

Fig. 5 SMS for a Israel Coastal Aquifer (ICA) and b Cyprus Akrotiri Aquifer (CAA). Aquifer conditions are characterized by the scaled quantities $\ell_{\mathrm{w}} / L$ and $\ell_{\mathrm{w}} / H_{\text {sea }}$, for two pumping locations, with the black dotted lines tracing the remaining groundwater flow $q_{\mathrm{r}}$ directly after pumping with the current rate under variable recharge and boundary inflows. (a) ICA: current pumping position at $3 \mathrm{~km}$ from the coast (1), and hypothetical pumping position moved more inland to $10 \mathrm{~km}$ (2) and (b) CAA: current pumping position at $1 \mathrm{~km}$ from the coast (1), and hypothetical pumping position moved more inland to $2 \mathrm{~km}(2)$. Figs. S6 for ICA and S7 for CAA in Online Material 2 show further details of the modelled characteristics of the two aquifer cases

We furthermore calculate the site-specific SMS after hypothetically relocating the pumping to $10 \mathrm{~km}$ from the coastline, yielding $\ell_{\mathrm{w}} / L=0.5$ and $\ell_{\mathrm{w}} / H_{\text {sea }}=50$. Under current pumping and recharge rate then, $q_{\mathrm{r}}$ becomes negative (x-mark, Fig. 5a), which implies that the critical condition would switch from well intrusion $\left(\ell_{\mathrm{T}}=\ell_{\mathrm{w}}\right.$, Fig. 1b) to complete 
intrusion $\left(\ell_{\mathrm{T}}=\ell_{\text {div }}\right.$, Fig. 1a). The complete intrusion condition is critical for $r \geq 32 \mathrm{~mm} \mathrm{yr}^{-1}$, as the lower limit $q_{\mathrm{r}}^{\mathrm{min}}$ falls in the negative part of the sustainable space for this $r$-range.

Figure 5a also traces (dotted lines) the site-specific upper limit of $q_{\mathrm{r}}$ for different recharge $r$ with the current pumping $q_{\mathrm{w}}$ applied to the two different representative well locations $\ell_{\mathrm{w}}$. For the current pumping location at $\ell_{\mathrm{w}}=3 \mathrm{~km}$, the current pumping rate is unsustainable for $r \leq 230 \mathrm{~mm} \mathrm{yr}^{-1}$, because the $q_{\mathrm{r}}$-trace for this pumping intersects the $q_{\mathrm{r}}{ }^{\mathrm{min}}$ line at that $r$ value. For the hypothetical pumping at $\ell_{\mathrm{w}}=10 \mathrm{~km}$, the minimum required recharge for sustainability is $204 \mathrm{~mm} \mathrm{yr}^{-1}$ under the current pumping rate. For both pumping-location cases, and particularly for the current one, the minimum required recharge is close to the current recharge $r=240 \mathrm{~mm} \mathrm{yr}^{-1}$. Thus, well intrusion is a real threat under expected future hydro-climatic change and/or increased human use of the coastal groundwater at this site. Moving the pumping inland to $\ell_{\mathrm{w}}=10 \mathrm{~km}$ may evade the critical well intrusion condition, but complete SWI and associated loss of the fresh groundwater resource as far inland as $\ell_{\mathrm{T}}=\ell_{\text {div }}=5305 \mathrm{~m}$ is then threatening the aquifer under changed hydro-climate and/or human freshwater use.

\subsubsection{Cyprus Akrotiri Aquifer (CAA)}

The area of the CAA is $\sim 40 \mathrm{~km}^{2}$, its depth at the coastline is $H_{\text {sea }} \approx 50 \mathrm{~m}$, with $L / H_{\text {sea }}=60$, the inclination of its $3-\mathrm{km}$ long base is $1.7 \%$ and mean hydraulic conductivity $K=28 \mathrm{~m} \mathrm{~d}^{-1}$, and replenishment is $r=92 \mathrm{~mm} \mathrm{yr}^{-1}$ and (in this case known prevailing) boundary inflow $\left|q_{\mathrm{b}}\right|=549 \mathrm{~m}^{2} \mathrm{yr}^{-1}$; pumping is $q_{\mathrm{w}}=500 \mathrm{~m}^{2} \mathrm{yr}^{-1}$ at $\ell_{\mathrm{w}}=1 \mathrm{~km}$ (Mazi 2000; Koussis 2001; Mazi et al. 2004a, 2004b). The interface toe position for these current conditions is calculated by the analytical model to be $\ell_{\mathrm{T}}=640 \mathrm{~m}$ (Mazi et al. 2014).

Figure $5 \mathrm{~b}$ shows the SMS for the resulting current values $\ell_{\mathrm{w}} / L=0.33$ and $\ell_{\mathrm{w}} / H_{\text {sea }}=20$ under variable recharge; the cross $(+)$ indicates the current remaining groundwater flow $q_{\mathrm{r}}$ after pumping. For the current representative pumping location, the positive $q_{\mathrm{r}}(+$ mark $)$ implies that the pumped water originates landward of the well. The $q_{\mathrm{r}}{ }^{\min }$ line, falling in the positive part of the SMS, indicates also well intrusion $\ell_{\mathrm{T}}=\ell_{\mathrm{w}}$ (Fig. 1b) as the current critical condition, holding as long as $r \leq 268 \mathrm{~mm} \mathrm{yr}^{-1}$ and the boundary inflow is $\left|q_{\mathrm{b}}\right| \leq 406 \mathrm{~m}^{3} \mathrm{~m}^{-1} \mathrm{yr}^{-1}$ (analysis for the latter limit not shown); if groundwater replenishment exceeds these values, the lower limit $q_{\mathrm{r}}$ min falls in the negative part of the SMS and complete intrusion $\left(\ell_{\mathrm{T}}=\ell_{\text {div }}\right.$, Fig. 1a) becomes the critical condition.

We also calculate the associated SMS for hypothetic relocation of the representative well to $\ell_{\mathrm{w}}=2 \mathrm{~km}$, yielding $\ell_{\mathrm{w}} / L=0.5$ and $\ell_{\mathrm{w}} / H_{\text {sea }}=40$ (Fig. 5b). The positive $q_{\mathrm{r}}$-value (x mark) implies that all current pumping is then still satisfied from the area landwards of the well, as it is also for the current $\ell_{\mathrm{w}}=1 \mathrm{~km}$. However, for $\ell_{\mathrm{w}}=2 \mathrm{~km}$, the lower limit $q_{\mathrm{r}}^{\text {min }}$ lies in the negative part of the sustainable space for $r>22 \mathrm{~mm} \mathrm{yr}^{-1}$ and boundary inflow $\left|q_{\mathrm{b}}\right|>363 \mathrm{~m}^{3} \mathrm{~m}^{-1} \mathrm{yr}^{-1}$ (analysis for the latter limit not shown), which switches the critical condition from the former well intrusion to complete intrusion.

Figure $5 \mathrm{~b}$ shows further the trace (dotted) of the site-specific upper $q_{\mathrm{r}}$ limit for different $r$ (with the $r$ value range also associated with a $\left|q_{\mathrm{b}}\right|$ range, not shown), under the current pumping rate applied at the two investigated pumping locations. For the current well location $\ell_{\mathrm{w}}=1 \mathrm{~km}$, the current pumping rate is unsustainable under $\mathrm{a} \sim 20 \%$ decrease of the replenishment, i.e., for $r<64 \mathrm{~mm} \mathrm{yr}^{-1}$ and $\left|q_{\mathrm{b}}\right|<476 \mathrm{~m}^{3} \mathrm{~m}^{-1} \mathrm{yr}^{-1}$, as the intersection of the dotted line with the $q_{\mathrm{r}}^{\mathrm{min}}$ line indicates. For the hypothetical pumping at $\ell_{\mathrm{w}}=2 \mathrm{~km}$, sustaining the current pumping rate requires a minimum recharge $r=49 \mathrm{~mm} \mathrm{yr}^{-1}$ and boundary inflow $\left|q_{\mathrm{b}}\right|=433 \mathrm{~m}^{3} \mathrm{~m}^{-1} \mathrm{yr}^{-1}$, which would be a decrease of the current replenishment by $\sim 30 \%$. In the CAA case, the 
prevailing relatively large boundary inflow $\left|q_{\mathrm{b}}\right|$ prevents the remaining flow $q_{\mathrm{r}}$ from actually decreasing to zero, as it might in principle do in the ICA case.

\section{Discussion}

Overall hydro-climatic changes influence the marine and/or inland forcing of coastal aquifers, which then respond to the changed forcing according to their specific characteristics. In contrast to the overall hydro-climatic changes and the naturally given aquifer geometry and conditions, the location and rate of groundwater pumping is a human-controlled intervention and must therefore be an essential element of groundwater-resources management under hydro-climatic regime changes. The focus is then here on providing managers of coastal aquifers with a planning tool for sustainable exploitation of the groundwater resource that can as far as possible meet freshwater demand, taking into account a changing hydro-climatic forcing and the given aquifer geometric and hydrogeological conditions, while avoiding critical tipping points.

The mean macro-characteristics of a regional aquifer, $H_{\text {sea }}, K, L, \sin \varphi, r, q_{\mathrm{b}}, \ell_{\mathrm{w}}$ and $q_{\mathrm{w}}$, can be estimated reasonably well and, based on these and various scenarios for the hydro-climatic forcing, the limits for sustainability can be determined in terms of the groundwater flow $q_{\mathrm{r}}$ left in the aquifer immediately after the pumping location, or equivalently the submarine discharge $q_{\mathrm{SD}}$ into the sea. Performing such analysis for a regional coastal aquifer, with certain slope, $K$ value and key geometrical macro-characteristics (expressed as $\ell_{\mathrm{w}} / H_{\text {sea }}$ and $\ell_{\mathrm{w}} / L$ ) over a relevant range of recharge $r$ (and possible non-zero boundary flow $\left|q_{\mathrm{b}}\right|$ ) values, yields that aquifer's SMS and its bounding $q_{\mathrm{r}}(r)$ curves for various pumping rates $q_{\mathrm{w}}$; that analysis also informs on how the pumped groundwater $q_{\mathrm{w}}$ partitions between the zone $0<\ell \leq \ell_{\mathrm{w}}$ on the seaside and the zone $\ell_{\mathrm{w}} \leq \ell \leq L$ on the landside of the representative pumping location $\ell_{\mathrm{w}}$. The theoretical, general total SMS is obtained for all possible $0<\ell_{\mathrm{w}} / H_{\text {sea }} \rightarrow \infty$ and contains all the different specific SMS corresponding to any actual, finite site-specific $\ell_{\mathrm{w}} / H_{\text {sea }}$ value (past, current or future).

From the results for the general total SMS emerges as general rule of thumb that the total general SMS is practically applicable across the entire range of investigated recharge conditions, from dry $\left(r \leq 100 \mathrm{~mm} \mathrm{yr}^{-1}\right)$ to wet $\left(r=1000 \mathrm{~mm} \mathrm{yr}^{-1}\right)$, for sites characterized by either $\ell_{\mathrm{w}} / H_{\text {sea }}>40$ or a low hydraulic conductivity $K \leq 1 \mathrm{~m} \mathrm{~d}^{-1}$ (and aquifer slopes $\sim 1 \%$; see effects of different slopes in Mazi et al. (2013)). Furthermore, $q_{\mathrm{r}}$ can be negative for any well location in the aquifer if $K \leq 1 \mathrm{~m} \mathrm{~d}^{-1} ; q_{\mathrm{r}}$ can also be negative for any $K$-value if $\ell_{\mathrm{w}} / H_{\text {sea }}>40$.

For the complementary aquifer conditions $K>1 \mathrm{~m} \mathrm{~d}^{-1}$ and $\ell_{\mathrm{w}} / H_{\text {sea }} \leq 40$, it is instead prudent to maintain positive $q_{\mathrm{r}}$. This restriction leaves small opportunities for use of coastal groundwater in regions of low recharge and/or for pumping locations that are already far inland from the coastline ( $\ell_{\mathrm{w}} / L$ close to 1 , e.g., due to already progressed seawater intrusion), particularly if the aquifer does not receive much inflow from farther inland areas to enhance the flow derived from the groundwater recharge within the coastal region itself.

Results thus indicate the ratios $\ell_{\mathrm{w}} / H_{\text {sea }}$ and $\ell_{\mathrm{w}} / L$ as suitable indicators for estimating the risk of SWI under various groundwater exploitation conditions; e.g., under stable recharge $r$, greater pumping rate $q_{\mathrm{w}}$ is sustainable at sites with relatively large $\ell_{\mathrm{w}} / H_{\text {sea }}$-values (small aquifer depth below sea level). However, as the representative well location moves inland and $\ell_{\mathrm{w}} / L$ increases, the critical aquifer condition may change from one of well intrusion (Fig. 1a) to one of complete intrusion (Fig. 1b). The interface toe location is more sensitive 
to $\ell_{\mathrm{w}} / H_{\text {sea }}$ than to $r / K$. Therefore, given an aquifer geometry $L / H_{\text {sea }}$, decisions regarding pumping locations can be taken mainly by evaluating the ratio $\ell_{\mathrm{w}} / H_{\text {sea }}$ for each possible pumping location $\ell_{\mathrm{w}} / L$.

The specific SMS has here been concretely determined for the specific aquifer case of ICA, for possible representative well locations at $\ell_{\mathrm{w}}=3$ (current) and $10 \mathrm{~km}$ (hypothetical) and for aquifer depth at the coast $H_{\text {sea }}=200 \mathrm{~m}$. Since for $\ell_{\mathrm{w}}=10 \mathrm{~km}$ the ratio $\ell_{\mathrm{w}} / H_{\text {sea }}=50$ (i.e., $>40$ ) and $K=30 \mathrm{~m} \mathrm{~d}^{-1}$, the simple rule of thumb allows here negative $q_{\mathrm{r}}$ (Fig. 5), which implies that pumping of some coastal groundwater also from seawards of the representative well location can be sustainable. The calculated specific SMS can be used to also examine aquifer management alternatives under different recharge and pumping scenarios; e.g., if recharge in the ICA decreases by more than $5 \%$ of the current value, today's pumping rate will not be sustainable. In contrast, if more recharge is applied, e.g., $+8 \%$ through artificial recharge, an additional rate of $12 \%$ of the current $q_{\mathrm{w}}$ could be pumped sustainably.

In the other concrete aquifer case investigated here, the CAA case, the specific SMS was calculated for representative well locations $\ell_{\mathrm{w}}=1$ (current) and $2 \mathrm{~km}$ (hypothetical) from the coast. For $\ell_{\mathrm{w}}=2 \mathrm{~km}$, the simple rule of thumb is on the limit of allowing pumping groundwater also from seaward of the well (i.e., of allowing $q_{\mathrm{r}}<0$ ), because in that case $\ell_{\mathrm{w}} / H_{\text {sea }}=40$ and $K=28 \mathrm{~m} \mathrm{~d}^{-1}>1 \mathrm{~m} \mathrm{~d}^{-1}$. In this particular case, calculations show that, by disregarding the rule of thumb and allowing $q_{\mathrm{r}}<0$, the maximum pumping rate might be increased but only by $8.6 \%$, taking then also the risk that the coastal aquifer could be lost by complete SWI as a result of, e.g., a small decline of the natural replenishment of fresh groundwater (recharge plus some boundary inflow in this case). Furthermore, examining the specific SMS for variable aquifer replenishment shows that the current pumping rate would not be sustainable, from either pumping location, if the replenishment were to decline, e.g., due to climate change, by $\sim 20 \%$ for $\ell_{\mathrm{w}}=1 \mathrm{~km}$ and by $\sim 30 \%$ for $\ell_{\mathrm{w}}=2 \mathrm{~km}$.

\section{Conclusions}

The simple analytical rules and bounds derived here quantify an SMS for human use of coastal groundwater in general terms that are applicable across different regional scales and parts of the world. Specifically, this quantification identifies and relates the SMS to the key human controls $\left(\ell_{\mathrm{w}} / L, \ell_{\mathrm{w}} / H_{\mathrm{sea}}\right)$ and the overall mostly naturally given forcing (mainly indicated by $H_{\text {sea }} / L$ and less so by $r / K$; with higher bed slope expanding the SMS) that determine SWI under different coastal aquifer conditions. Without being global sums or averages of some single variables, these controls quantify the SMS boundaries by accounting for the wideranging local-regional variability that exists across the world's coastal regions.

Since in most cases of practical interest the average aquifer hydraulic conductivity may be assumed to be $K>1 \mathrm{~m} \mathrm{~d}^{-1}$, the actual site-specific SMS will be typically restricted relative to the general total SMS. To achieve a pumping rate that can as far as possible meet certain freshwater demand, a manager of a coastal aquifer should select pumping locations such that $\ell_{\mathrm{w}} / H_{\text {sea }}>40$, thereby possibly allowing for sustainable drawing of groundwater also from seaward of the pumping location $\left(q_{\mathrm{r}}<0\right)$. For each human-determined pair of control variables $\left(\ell_{\mathrm{w}}, q_{\mathrm{w}}\right)$, the proximity of the interface toe to critical SWI conditions (well intrusion or complete coastal aquifer intrusion) must be evaluated (Figs. 2a and 3) and, then, a possible increase in pumping rate must be weighed against the incurred higher intrusion risk. For a preliminary pumping selection ( of $\ell_{\mathrm{w}}, q_{\mathrm{w}}$ ), the sensitivity of SWI to a possible reduction of 
natural recharge $r$ must be also investigated. If the exploitation opportunities are tight, the option of artificial recharge enhancement can be gauged by analysing the resulting SMS under variable $r$ (Fig. 2b). By further extending the present basic deterministic analysis to a stochastic analysis, a more complete and ultimately more appropriate framework can be developed for assessing gains and risks of the various human selections for groundwater management; such an approach will be presented in a future work.

In general, accounting for local-regional variability is essential for sustainable management of human freshwater use. Managers, planners and policy-makers responsible for water resources, environmental sustainability and climate adaptation must decide their strategies and operations in direct relation to prevailing local-regional conditions identified by the aforementioned key controls. Regarding these practical needs, but also the related scientific perspectives, the quantification of the SMS developed here is sufficiently simple and general to enable consistent regional assessment, cross-regional comparison, and larger-scale aggregation of multiple regions (up to the global scale) for coastal groundwater resources under current conditions and future change scenarios of human water-use/demand, hydro-climate and sea level.

Acknowledgments This research has been supported by the Navarino Environmental Observatory (NEO), the Nova R\&D project KLIV, Stockholm University's strategic research program Ekoklim and the Swedish Research Council Formas (Project No. 2014-43).

\section{Compliance with Ethical Standards}

Conflict of Interest None.

\section{Human and Animal Rights No.}

Informed Consent Not applicable

Open Access This article is distributed under the terms of the Creative Commons Attribution 4.0 International License (http://creativecommons.org/licenses/by/4.0/), which permits unrestricted use, distribution, and reproduction in any medium, provided you give appropriate credit to the original author(s) and the source, provide a link to the Creative Commons license, and indicate if changes were made.

\section{References}

Bring A, Asokan SM, Jaramillo F, et al. (2015) Implications of freshwater flux data from the CMIP5 multi-model output across a set of northern hemisphere drainage basins. Earth's Future. doi:10.1002/2014EF000296

Destouni G, Prieto C (2003) On the possibility for generic modeling of submarine groundwater discharge. Biogeochem 66:171-186

Destouni G, Hannerz F, Prieto C, et al. (2008) Small unmonitored near-coastal catchment areas yielding large mass loading to the sea. Glob Biogeochem Cycles 22:GB4003

Destouni G, Jaramillo F, Prieto C (2013) Hydroclimatic shifts driven by human water use for food and energy production. Nat Clim Chang 3:213-217

Döll P (2009) Vulnerability to the impact of climate change on renewable groundwater resources: a global-scale assessment. Environ Res Lett. doi:10.1088/1748-9326/4/3/035006

Ferguson G, Gleeson T (2012) Vulnerability of coastal aquifers to groundwater use and climate change. Nat Clim Chang. doi:10.1038/nclimate1413

Ferguson IM, Maxwell RM (2012) Human impacts on terrestrial hydrology: climate change versus pumping and irrigation. Environ Res Lett 7:044022

Jaramillo F, Destouni G (2014) Developing water change spectra and distinguishing change drivers worldwide. Geophys Res Lett 41(23):8377-8386 
Jaramillo F, Destouni G (2015) Local flow regulation and irrigation raise global human water consumption and footprint. Science 350(6265):1248-1251

Koussis AD (ed) (2001) WASSER: Utilisation of Groundwater Desalination and Wastewater Reuse in the Water Supply of Seasonally-Stressed Regions. Final Project Report, with Appendices, National Observatory of Athens, Athens, Greece

Koussis AD, Mazi K, Destouni G (2012) Analytical single-potential, sharp-interface solutions for regional seawater intrusion in sloping unconfined coastal aquifers, with pumping and recharge. J Hydrol 416-417: 1-11. doi:10.1016/j.jhydrol.2011.11.012

Koussis AD, Mazi K, Riou F, Destouni G (2015) A correction for Dupuit-Forchheimer interface flow models of seawater intrusion in unconfined coastal aquifers. J Hydrol 525:277-285. doi:10.1016/j.jhydrol.2015.03.047

Koussis AD, Georgopoulou E, Kotronarou E et al (2010a) Cost-efficient management of coastal aquifers via recharge with treated wastewater and desalination of brackish groundwater: General framework. Hydrol Sci J. doi:10.1080/02626667

Koussis AD, Georgopoulou E, Kotronarou E et al (2010b) Cost-efficient management of coastal aquifers via recharge with treated wastewater and desalination of brackish groundwater: Application to the Akrotiri basin and aquifer, Cyprus. Hydrol Sci J. doi:10.1080/02626667

Leas EC, Dare A, Al-Delaimy WK (2014) Is gray water the key to unlocking water for resource-poor areas of the Middle East, North Africa, and other arid regions of the world? Ambio. doi:10.1007/ s13280-013-0462-y

Lenton TM (2011) Early warning of climate tipping points. Nat Clim Chang 1:201-209. doi:10.1038/ nclimate1143

Llamas R, Custodio E (eds) (2003) Introductory considerations and chapter 1. Intensive Use of Groundwater. Challenges and opportunities. Balkema, Swets \& Zeitlinger Publishers, Lisse, the Netherlands, In

Loáiciga HA, Pingel TJ, Garcia ES (2012) Sea water intrusion by sea-level rise: scenarios for the twenty-first century. Ground Water 50:37-47

Masterson JP, Garabedian SP (2007) Effects of sea-level rise on ground water flow in a coastal aquifer system. Ground Water 45:209-217

Mazi A (2000) Optimisation of a model for the hydrologic balance with groundwater data. National Technical University of Athens, Graduate Thesis (in Greek)

Mazi A (2014) Seawater intrusion risks and controls for safe use of coastal groundwater under multiple change pressures, dissertations Department of Physical Geography and Quaternary Geology no 42, Stockholm University. Stockholm, Sweden, US-AB

Mazi K, Koussis AD, Restrepo P, Koutsoyiannis D (2004a) A groundwater-based, objective-heuristic parameter optimisation method for the PRMS model: the Akrotiri Basin, Cyprus application. J Hydrol 290:243-258. doi:10.1016/j.jhydrol.2003.12.006

Mazi K, Koussis AD, Restrepo P, Koutsoyiannis D (2004b) A groundwater-based, objective-heuristic parameter optimisation method for the PRMS model: the Akrotiri Basin. Cyprus application, Erratum J Hydrol 299: 160-161. doi:10.1016/j.jhydrol.2004.09.017

Mazi K, Koussis AD, Destouni G (2013) Tipping points for seawater intrusion in coastal aquifers under rising sea level. Environ Res Lett 8:014001 (6pp). doi:10.1088/1748-9326/8/1/014001

Mazi K, Koussis AD, Destouni G (2014) Intensively exploited Mediterranean aquifers: resilience and proximity to critical points of seawater intrusion. Hydrol Earth Syst Sci. doi:10.5194/hess-181663-2014

Nicholls RJ, Klein RJT (2005) Climate change and coastal management on Europe's coast. In: Vermaat J, Bouwer L, Turner K, Salomons W (eds) Managing European coasts. Past, Present and Future, Springer, Heidelberg, Berlin, pp. 199-226

Parry ML, Canziani OF, Palutikof JP, et al. (eds) (2007) Climate change 2007: impacts, adaptation and vulnerability. Cambridge University Press, Cambridge, UK, Contribution of Working Group II to the Fourth Assessment Report of the Intergovernmental Panel on Climate Change

Post VEA (2005) Fresh and saline groundwater interaction in coastal aquifers: is our technology ready for the problems ahead? Hydrogeol J 13:120-123

Postel S (1997) Last oasis. W.W. Norton \& Co., New York

Prieto C, Destouni G (2011) Is submarine groundwater discharge predictable? Geophys Res Lett 38:L01402. doi: 10.1029/2010GL045621

Prieto C, Destouni G (2005) Quantifying hydrological and tidal influences on groundwater discharges to coastal waters. Water Resour Res 41:W12427

Prieto C, Kotronarou A, Destouni G (2006) The influence of temporal hydrological randomness on seawater intrusion in coastal aquifers. J Hydrol 330:285-300

Sanford WE, Pope JP (2010) Current challenges in forecasting saltwater intrusion: lessons from the eastern shore of Virginia. Hydrogeol J 1:73-93 
Small EE (2005) Climatic controls on diffuse groundwater recharge in semiarid environments of the southwestern United States. Water Resour Res. doi:10.1029/2004WR003193

Stigter TY, Varanda M, Bento S, et al. (2015) Combined assessment of climate change and socio-economic development as drivers of freshwater availability in the south of Portugal. Water Resour Manag. doi:10. 1007/s11269-015-0994-y

Strack ODL (1976) A single-potential solution for regional interface problems in coastal aquifers. Water Resour Res. doi:10.1029/WR012i006p01165

Webb MD, Howard KWF (2011) Modeling the transient response of saline intrusion to rising sea-levels. Ground Water. doi:10.1111/j.1745-6584.2010.00758.x

Werner AD, Simmons CT (2009) Impact of sea-level rise on sea water intrusion in coastal aquifers. Ground Water. doi:10.1111/j.1745-6584.2008.00535.x

Werner AD, Alcoe DW, Ordens CM, et al. (2011) Current practice and future challenges in coastal aquifer. FluxBased and Trigger-Level Approaches with Application to an Australian Case Study. Water Resour Manage, Management. doi:10.1007/s11269-011-9777-2

Werner AD, Ward JD, Morgan LK, et al. (2012) Vulnerability indicators of sea water intrusion. Ground Water 50: 48-58. doi:10.1111/j.1745-6584.2011.00817.x

Zuurbier KG, Raat KJ, Klaasjan J, et al. (2016) How subsurface water technologies (SWT) can provide robust, effective, and cost-efficient solutions for freshwater Management in Coastal Zones. Water Resour Manag. doi:10.1007/s11269-016-1294-x 